\title{
Biological Fabrication and Characterization of Zinc Oxide Nanoparticles Using Gymnema Sylvestre Potentially Produces Toxicity in Breast Cancer Cells -MCF-7
}

\section{Murali Santhoshkumar}

Department of Biotechnology, Thiruvalluvar University, Vellore, Serkkadu-632115, Tamilnadu, India Agilan Balupillai

Department of Biotechnology, Thiruvalluvar University, Vellore, Serkkadu-632115, Tamilnadu, India Ernest David ( $\nabla$ ernestdavid2009@gmail.com )

Department of Biotechnology, Thiruvalluvar University, Vellore, Serkkadu-632115, Tamilnadu, India

Original Research Full Papers

Keywords: Gymnema sylvestre, ZnONPs, Toxicity, Breast cancer, Apoptosis

Posted Date: February 3rd, 2021

DOl: https://doi.org/10.21203/rs.3.rs-161267/v1

License: (c) (1) This work is licensed under a Creative Commons Attribution 4.0 International License. Read Full License 


\section{Abstract}

To study the biological fabrication and characterization of zinc oxide nanoparticles (ZnO NPs) using Gymnema sy/vestre and their toxicity to breast cancer cells MCF-7.In the existing work, ZnO NPs were synthesized using leaf extract of the Indian medicinal plant Gymnema sy/vestre and it was characterized by Particle size, Zeta potential, FT-IR, XRD and SEM analyses. This ZnO NPs to have potentially validated anticancer role in breast cancer cells MCF-7 in vitro approach. The plant-based synthesized ZnO NPs were evaluated against the inhibitory role on breast cancer cell lines. We significantly observed that ZnO-NPs induce efficient toxicity of MCF-7 cells by increasing ROS, mitochondrion membrane damage and apoptotic morphological alterations. These results stated that ZnO-NP induces Bax and Caspases and down-regulates Bcl-2 proteins in MCF-7 cells. Thus, the biologically synthesized ZnO NPs were identified as good performance to inhibit breast cancer cell growth even at low concentrations.

\section{Introduction}

Breast cancers have concern as furthermost predominant cancer and also more aggressive type of cancer in the women worldwide [1]. Moreover, breast cancer has shown in global epidemic due to the highest metastatic condition. Closely, there are 250000 breast cancer patients are diagnosed with metastatic condition in the United Nation, and 40000 more patients were died for this disorder. [2].In the developing countries especially in India, second most common cancer after cervix cancer [3]. Breast cancer could be referring to a malignant arrangement of tumour that has been settled from cells are highly proliferated in the breast tissue [4]. This kind of cancer being treated with several chemotherapy and radiation therapy that could be ends up in several side effects due to the nonexistence target specificity. This toxicity not only affects tumour tissues, but also disturbs healthy and normal cells [5]. These methods are reducing the risk of cancer but not ensure the complete eradication of the cancer cells [6]. Furthermore, reoccurrence of the disease has been pointed that use of chemotherapy can be failure or cancer cells become resistance against chemotherapy [7]. Chemotherapy based potential toxicity on the cancer cells are undergone increased side effects which are mainly associated with insufficient specificity for cancer cells that signifies a major restriction in this type of therapy. Therefore, it is very useful to find out a safe and effective approach to combat the life-threatening disease especially for treating breast cancer [8].

Research related to nanotechnology depended cancer therapy covers yonder drug delivery systems in the construction of new therapeutical potential pharmacological approaches. Advances in nanotechnology put forward the use of medicinal plants for the synthesis of various nanoparticles. It shall be used for treating various diseases owing to its low toxicity and increased target specificity. The nanoparticles fabricated with plant extracts were proven to demonstrate various biological activities [9]. Zinc oxide nanoparticle ( $\mathrm{nnO} N P s$ ) is a key ingredient of several enzymes, ointments and sun screens that aids in treatment of pain and inflammation [10]. Synthesis of ZnO NPs belongs to metal nanomaterials and its exhibits promising pharmacological activities such as anti-bacterial, antitumoral, anti-viral due to its morphology, exposure time, particle size, concentration, and biocompatibility [11]. ZnO NPs, with their 
exclusive properties such as biocompatibility with selective target specificity, enhanced cytotoxicity on the cancer cells and easy way to biosynthesis and auspicious anticancer agent [12].

Since ancient times, plants have been used in the treatment of human disease. In Ayurvedic system of medicine, several thousands of plants are being used for curing various diseases [13]. Gymnemasy/vestre is one among such plants belongs to the family Asclepiadaceae and known as "Madhunashini" (sweet destructor) in Sanskrit language due to its anti-diabetic property. It has been used in the treatment of diabetes, obesity and snake bites. All these properties can be attributed to the bioactive phytochemicals present in this plant $[14,15]$. With this perspective, the present work was carried out to synthesize ZnO NPs using the leaf extract of G.sylvestre and potentially validate anticancer role in breast cancer cells MCF-7 in vitro approach.

\section{Materials And Methods \\ 2.1. Materials}

Zinc nitrate (SD-Fine chemicals), MCF-7 cells, (National centre for cell sciences, Pune), DMEM, PBS, Trypsin (Hyclone), MTT, (Himedia laboratories); DPPH (Sigma-Aldrich Fine Chemicals).

\subsection{Plant sample collection and preparation of ZnONPs}

Leaves of G.sylvestre were visually identified from the Acharya N G Ranga Agricultural University, Tirupati, Andhra Pradesh, India. Fresh and sterile leaves weighing about 5 grams were cut into fine pieces and was rinsed with distilled $\mathrm{H}_{2} \mathrm{O}$ and boiled with $\mathrm{H}_{2} \mathrm{O}$ for 15 min at $70^{\circ} \mathrm{C}$. Boiled mixture was filtered using Whatman No. 1 filter paper and the supernatant of leaf extract was collected and $90 \mathrm{ml}$ of $1 \mathrm{Mm}$ zinc nitrate solution was added. The reaction mixture was left for overnight. The colour change from colour less to pale yellow colour indicate the formation of ZnO NPs [16].

\subsection{Characterization of nanoparticles}

In this study, the colour changing ability reaction combination was well-thought-out as the pilot event to detect the nanoparticle synthesis. FT-IR spectrum analysis was used by FT-IR-ALPHA interferometer instrument (Bruker, Germany) and the scanning range between 500 to $4000 \mathrm{~cm}-1$. Horiba nanopartical analyser was employed to regulate the exact average size and Zeta potential values of the synthesized nanoparticles. The average size of bio fabricated ZnONP-GS was determined by XRD-6000-Shimadzu Analytical, India, Scanning Electron Microscope (SEM- FEIQuanta, 200 FEGHRSEM equipped with EDAX).

\subsection{Cell culture}

MCF-7 human breast cancer cell lines were routinely maintained in DMEM (Dulbecco's modified Eagle's medium) supplemented with $2 \mathrm{mM} / \mathrm{L}$ glutamine, $10 \%$ foetal bovine serum (FBS) and $10 \mu \mathrm{g} / \mathrm{ml}$ of ciprofloxacin in a $5 \% \mathrm{CO}_{2}$ atmosphere at $37^{\circ} \mathrm{C}$ [17].

\subsection{Cytotoxicity assay}


The cytotoxic activity of the ZnO NPs were screened by MTT (3-(4, 5-Dimethylthiazol-2-

yl)-2,5diphenyltetrazoliumbromide) assay [18]. The MCF-7 cells $\left(0.2 \times 10^{6} /\right.$ well) were equally seeded in 96 well plates and kept 24 hours incubation at $37^{\circ} \mathrm{C}$ in $5 \% \mathrm{CO}_{2}$. After grown the cells, it can be treated with different concentrations of the ZnO NPs viz.1, 2,3,4,5,10,20,30 and $40 \mu \mathrm{g} / \mathrm{ml}$ respectively. After 24 hours of incubation with the test compounds, $0.02 \mathrm{ml}$ of MTT reagents were equally added to each well and incubation was continued for another 4 hours. Moreover, $0.02 \mathrm{ml}$ of DMSO was equally given to all the wells to solubilise the formazan crystals and the colorimetric absorbance reading was detected by Micro plate reader at $570 \mathrm{~nm}$ [19].

\subsection{DCFH-DA staining}

Inner cellular ROS fabrication was considered by fluorescence dye, DCFH-DA,DCFH-DA penetrate cells passively and transformed to $\mathrm{DCFH}$, which responses by reactive oxygen species for the formation of fluorescent DCF. MCF-7 cells stayed scattered on the top edge of cover slips in 24 well plates and supplemented with ZnO NPs for 60 mins. Then cells were nurtured with $25 \mu \mathrm{M}$ DCFH-DA for about half an hour. The fluorescence concentration was resolute at 490nm in excited level and 540nm emission level by means of fluorescence microplate reader (Sunnyvale, California, USA) similarly [20].

\subsection{Acridine orange/ethidium bromide staining}

To envisage the nuclear variations and characteristics of apoptosis, that is apoptotic body formation, dual staining was done by standard protocol [21]. ZnO NPs implored apoptotic variations in MCF-7 cells which were suspected by staining methods like acridine orange and ethidium bromide. Shortly, $1 \times 10^{6}$ cells were dispensed in 6-well plate then maintained MCF-7 cells were managed through ZnO NPs which is reserved for development or incubation period. Subsequent to development phase, the cells stood rinsed with ice cold phosphate buffered saline then discoloured with $10 \mu \mathrm{L}$ of acridine orange and $10 \mu \mathrm{L} / \mathrm{mg}$ ethidium solution at room temperature and saved for gestation for about $45 \mathrm{mins}$. The discoloured apoptotic and viable cells were scrutinized by glowing microscope [22].

\subsection{Western blot analysis}

Protein expression studies were done by western blotting technique in accordance with standard protocol. Crucial apoptotic intracellular signalling markers such as, Bax, caspase-3, 9 and Bcl-2 were examined by western blotting. Presently, $1 \times 10^{6}$ cells were treated with ZnO NPs and the proteins were extracted from cells by RIPA buffer that comprises cocktail protease enzyme. The concentration of protein was restrained by Nanodrop products, Thermo Fischer scientific, United States of America. Later the proteins were located to SDS-PAGE (10\%) and the gel was reallocated to membrane (PVDF). Then the membrane was jammed with bovine serum albumin (5\%) for more than $2 \mathrm{hrs}$. Again, membranes were pampered with a suitable primary antibody and it kept for $24 \mathrm{hrs}$ incubation at $4^{\circ} \mathrm{C}$. Moreover, it was further nurtured through apt conjugated secondary horseradish peroxidase antibodies for $1 \mathrm{hr}$. Resultant bands were recognized by using improved chemiluminescence underlying substance and band illumination were scrutinized by software image $\mathrm{J}[23]$. 


\subsection{Statistical Examination}

All experimentations stayed approved out in tierce self-destructive trials and the outcomes were expressed as the mean \pm standard deviation (Mean $\pm S D$ ) by means of one-way analysis of variance (ANOVA). Standards of $\mathrm{P}<0.05$ were symptomatic of substantial alterations and modifications.

\section{Results And Discussion}

\subsection{Synthesis of ZnO Nanoparticles from Gymnema sylvestre (ZnONP-GS) and its characterization studies}

Plants are instrumental in treating human diseases in almost every system of medicine worldwide [24]. Recent advances in nano biomedicine emphasize on the importance of green synthesis of metal nanoparticles using medicinal plants. This approach is advantageous over the physical and chemical methods due to safety, cost effectiveness and absence of toxic residues [25]. The synthesis of metal nanoparticles such as Ag, Au, Zn etc., have potential biological application especially it may inhibit cancer cell growth [26]. In this present work, we elaborately demonstrate the biologically synthesis and characterization of ZnO NPs from the medicinal plant Gymnema sy/vestre and it was evaluated in anticancer potential in MCF-7 breast cancer cells [27].

The biological synthesis of ZnO NPs from Gymnema sylvestre was initially conformed by the colour change of the reaction mixture from colourless to brown colour indicated the synthesis of ZnO NPs preliminarily. Then, the synthesized nanoparticles were exhibits as strongest UV absorbance peak at 300 nm (Fig. 1). Moreover, the particle size of the synthesized nanoparticles was analysed by Zeta potential and particle size analysis. The particle size and Zeta potential analysis revealed that $81.1 \mathrm{~nm}$ average size (Fig. 2). and - 25.1 mv zetapotential value (Fig. 3) of the synthesized nanoparticles. reported the synthesis of $\mathrm{Mg}^{2+}$ doped ZnO NPs using the leaf extract of Gsy/vestre. From the results it can be concluded that the synthesized nanoparticles are stable [28].

Moreover, active and functional biomolecules are present in the ZnO NPs synthesized from G.sy/vestre which are identified and analysed from FTIR spectrum and it is shown (Fig. 4). The FTIR spectrum exhibits the peaks at $3415 \mathrm{~cm}^{-1}$ were allotted to the extending vibrations of hydroxy groups; primary and secondary amines groups were presented in the synthesized nanoparticles respectively. The presented peaks were directly equivalent to protein and enzymes molecules or polysaccharides are found in the cell biomass. The peak at $2926,2854,2358$ and $2330 \mathrm{~cm}^{-1}$ were owed to symmetric and asymmetric stretching shaking of sp3 hybridized. The peak at 1612 and $1313 \mathrm{~cm}^{-1}$ were allocated to $C=0$ extending vibrations of the carbonyl group in ketones, aldehydes and functional carboxylic acids. Moreover, the peak at 1163 and $1055 \mathrm{~cm}^{-1}$ were allocated to vibration of $-\mathrm{C}=\mathrm{C}$-aromatic ring stretching. In addition to this band at $995 \mathrm{~cm}^{-1}$ resembles to metal binding interact with carboxylic $(M \leftrightarrow C \equiv 0)$ groups, this functional group might be acts template, reducing agent and capping of nanocrystals [29]. 
The crystal nature-based structure is often crucial conformation of $\mathrm{ZnO}$ nanomaterials which are determined by X-Ray diffraction (Fig. 5). In this study, obtains several crystal-based aspects of ZnO nanofabricated material. The X-Ray diffraction design of $\mathrm{ZnO}$ nanofabricated material are wurtzite hexagonal phase which designates the well indexed XRD peaks that has corresponding to the plane's values such as (34699), (30566), (44739), (64831) (77739) and (81869). This present result has been implying that the products comprised of pure phases. Moreover, the effective diffraction peaks were found more rigorous and narrower that implying a respectable crystalline structure of $\mathrm{Zn}$ nanofabricated products. The respectable of size range of $\mathrm{ZnO}$ nanofabricated material was from $20 \mathrm{~nm}$ to $100 \mathrm{~nm}$ [30].

As shown in the (Fig. 6) demonstrates the surface and shape with size morphology of $\mathrm{ZnO}$ were characterized from the microscopical studies of SEM. This study evident that ZnO NPs were spherical and irregular in shape and were poly-dispersed. The measured average size was $50 \mu \mathrm{m}$, Occasional agglomeration of the ZnO NPs has been observed. These all the characterization studies are scientifically evident that present nanoparticles are $\mathrm{ZnO}$ [31].

\subsection{Cytotoxic effect and intracellular ROS generation in ZnO nanoparticles synthesized from Gymnema} sylvestre against breast cancer MCF-7 cells

The ZnO NPs can be easily biodegraded or shall take part in nutritional cycle of the body [32]. These nanoparticles exhibit discriminating cytotoxicity over cancer cells [33]. ZnO NPs have ability to stimulate oxidative stress in cancer cells, which has been found to be one of the prime mechanisms of cytotoxicity. This property may be attributed to the semiconductor nature of ZnO NPs [34]. The cytotoxic event of ZnO NPs synthesized from Gymnema sylvestre in the breast cancer MCF-7 cells were evaluated by studies of MTT assay. Here we found that increasing concentration of ZnO NPs at the ranges from 10-100 $\mu \mathrm{g}$ for 24 hrs incubation notably reduces the cell viability in MCF-7 cells. The IC 50 value of the tested ZnONPGS exhibits $36 \mu \mathrm{g} / \mathrm{ml}$. In the current work, we have chosen $\mathrm{IC}_{50}$ value of $36 \mu \mathrm{g} / \mathrm{ml}$ and $\mathrm{IC}_{25}$ value of 50 $\mu \mathrm{g} / \mathrm{ml}$ of ZnONP-GS for further molecular studies [35]. (Fig. 7).

It also induces ROS generation and leads to oxidative stress, eventually ends up in cell death when the anti-oxidative capacity of the cell is exceeded [36]. DCFH-DA staining are highly used for detection of ZnO NP-GS treated MCF-7 cells. Untreated MCF-7 cells showed there is no significant production ROS staining. ZnO NP-GS treated MCF-7 cells showing magnificent production of ROS for 24 hours incubation by dose depended manner. This result indicated that synthesized ZnONP-GS induces oxidative stress in MCF-7 cancer cells. Our results also conform that ZnO NP produces cytotoxicity and high over production of ROS in MCF-7 cells that can be led to oxidative stress. Several in vitro studies witnessed the ZnO NPs shows selective cytotoxic activity against the cancer cells [37]. Moreover, reported the anticancer activity of silver nanoparticles bio functionalized using aqueous extract of G.sy/vestre against HT29 human colon adenoma cancer cells. Hanley also stated that ZnO NPs exhibited 28-35 times selective toxicity over cancerous cells when compared with normal cells [38]. ZnO NPs selectively kill cancer cells by inferring selective localization and selective cytotoxicity towards them [39]. (Fig. 8). 


\subsection{ZnONP-GS induces the production of ROS and apoptosis in MCF-7 cells}

High over production of ROS arbitrated oxidative stress leads to the programmed cell death [40]. Apoptosis is a crucial programmed cell death which has actively eliminated the cancer cells through whether intrinsic or extrinsic apoptotic signalling pathway [41]. In this present work, ZnONP-GS treatment associated morphological changes of apoptotic MCF-7 cells were test by double staining of acridine orange and ethidium bromide staining. Here, we noticed ZnONP-GS treated cells showed a greater number of apoptotic cells significantly in dose depended manner. Conversely, untreated MCF-7 cells showing there is no significant apoptotic cells conformed by green fluorescence staining [42]. (Fig. 9).

In addition, proapoptotic biomarkers such as Bax, caspases and antiapoptotic protein Bcl-2 are highly regulating apoptosis [43]. Apoptosis has been documented as dispensation over several machineries, including amendment of the intracellular mitochondrial depended pathway to stimulate the caspase cascade activation [44]. When the over production of ROS sprightly induces proaptotic mediators leads to apoptosis [45]. ZnO NPs treatment arbitrated apoptotic protein appearance was studied using western blotting analysis. As (Fig. 10) confirms an extensively increased protein expression of Bcl-2 and broadly decreased expression of Bax, caspase- 9 and 3 protein in untreated breast cancer cells. Suggestively, the expression of anti-apoptosis marker Bcl-2 was experientially to be less whereas the expression of proapoptotic mediators were relatively quite higher expression in ZnONPs-GS treatment in the MCF-7 cells. There are numerous documentation has been reported strongly that ZnONPs from several plant extracts induces proapoptotic markers in several cancer cell lines [46]. This result indicates that ZnONPsGS induces proapoptotic mediators leads to cell death [47].

\section{Conclusion}

Based on the results of this work, we concluded that the biologically synthesized $\mathrm{ZnO}$ nanoparticles from leaf extract of the medicinal plant G.sylvestre have been characterized. The studies from UV Spectra, Zeta potential, FTIR, SEM concluded that conforms the synthesis of ZnO NPs produced from G.sy/vestre. Then, the synthesized ZnONPs-GS have distinct role in the breast cancer MCF-7 cells by the producing toxicity, ROS and apoptosis. Moreover, our molecular experiments suggested that ZnO NPs -GS induces proapoptotic markers in MCF-7 cells.

\section{Declarations}

Conflicts of interest

None

\section{References}


1. Akram M, Iqbal M, Daniyal M, Khan AU (2017) Awareness and current knowledge of breast cancer. Biological research 50:33:1-23

2. Springer GF (1995) T and Tn pancarcinoma markers: autoantigenic adhesion molecules in pathogenesis, prebiopsy carcinoma-detection, and long-term breast carcinoma immunotherapy. Critical Reviews ${ }^{\mathrm{TM}}$ in Oncogenesis 6:57-85

3. Mittra I, Mishra GA, Singh S, Aranke S, Notani P, Badwe R, Miller AB, Daniel EE, Gupta S, Uplap P, Thakur MH (2010) A cluster randomized, controlled trial of breast and cervix cancer screening in Mumbai, India: methodology and interim results after three rounds of screening. International journal of cancer 126:976-84

4. Salamanna F, Borsari V, Pagani S, Brodano GB, Gasbarrini A, Fini M (2020) Development and characterization of a novel human 3D model of bone metastasis from breast carcinoma in vitro cultured and retaining the in vivo tumor microenvironment and cell heterogeneity. Bone 115773

5. Bentzen SM (2006) Preventing or reducing late side effects of radiation therapy: radiobiology meets molecular pathology. Nature Reviews Cancer 702-13

6. Chen DS, Mellman I (2013) Oncology meets immunology: the cancer-immunity cycle. Immunity 39:10

7. Panetta JC (1996) A mathematical model of periodically pulsed chemotherapy: tumor recurrence and metastasis in a competitive environment. Bulletin of mathematical Biology 5:425-47

8. Fu B, Wang N, Tan HY, Li S, Cheung F, Feng Y (2018) Multi-component herbal products in the prevention and treatment of chemotherapy-associated toxicity and side effects: A review on experimental and clinical evidences. Frontiers in Pharmacology 9:1394

9. Ansari SH, Islam F, Sameem M (2012) Influence of nanotechnology on herbal drugs: A Review. Journal of advanced pharmaceutical technology \& research 42

10. Siddiqi KS, ur Rahman A, Husen A (2018) Properties of zinc oxide nanoparticles and their activity against microbes. Nanoscale research letters 1-3

11. Saha M, Das AR. (2020) Nanocrystalline ZnO: A Competent and Reusable Catalyst for the Preparation of Pharmacology Relevant Heterocycles in the Aqueous Medium. Current Green Chemistry 53-104

12. Mohebbi S, Nezhad MN, Zarrintaj P, Jafari SH, Gholizadeh SS, Saeb MR, Mozafari M. (2019) Chitosan in biomedical engineering: a critical review. Current stem cell research \& therapy 93-116

13. Auddy B, Ferreira M, Blasina F, Lafon L, Arredondo F, Dajas F, Tripathi PC, Seal T, Mukherjee B (2003) Screening of antioxidant activity of three Indian medicinal plants, traditionally used for the management of neurodegenerative diseases. Journal of Ethnopharmacology 131-8

14. Okigbo RN, Eme UE, Ogbogu S (2008) Biodiversity and conservation of medicinal and aromatic plants in Africa. Biotechnology and Molecular Biology Reviews 127-34

15. Banjari I, Misir A, Pavlic M, Herath PN, Waisundara VY (2019) Traditional Herbal Medicines for Diabetes Used in Europe and Asia: Remedies from Croatia and Sri Lanka. Altern Ther Health Med 25:40-52 
16. Gomathi M, Prakasam A, Rajkumar PV, Rajeshkumar S, Chandrasekaran R, Anbarasan PM 2020 Green synthesis of silver nanoparticles using Gymnema sylvestre leaf extract and evaluation of its antibacterial activity. South African Journal of Chemical Engineering 32:1-4

17. Feinshtein V The Impact of Cannabidiol on MDR-P-gp and BCRP Transporters in the Human Placental Barrier(Doctoral dissertation, Ben-Gurion University of the Negev)

18. Hackenberg S, Scherzed A, Technau A, Kessler M, Froelich K, Ginzkey C, Koehler C, Burghartz M, Hagen R, Kleinsasser N (2011) Cytotoxic, genotoxic and pro-inflammatory effects of zinc oxide nanoparticles in human nasal mucosa cells in vitro. Toxicology in vitro 657-63

19. Boroumand Moghaddam A, Moniri M, Azizi S, Abdul Rahim R, Bin Ariff A, Navaderi M, Mohamad R (2017)Eco-friendly formulated zinc oxide nanoparticles: induction of cell cycle arrest and apoptosis in the MCF-7 cancer cell line. Genes 281

20. Yang B, Chen Y, Shi J (2019) Reactive oxygen species (ROS)-based nanomedicine. Chemical reviews 4881-985

21. Khanna N, Reddy VG, Tuteja N, Singh N. Differential gene expression in apoptosis: identification of ribosomal protein S29 as an apoptotic inducer. Biochemical and biophysical research communications 476-86.

22. Sivakumaran N, Samarakoon SR, Adhikari A, Ediriweera MK, Tennekoon KH, Malavige N, Thabrew I, Shrestha RL (2018) Cytotoxic and apoptotic effects of govaniadine isolated from Corydalis govaniana Wall. roots on human breast cancer (MCF-7) Cells. BioMed research international

23. lacomino G, Medici MC, Russo GL (2008) Valproic acid sensitizes K562 erythroleukemia cells to TRAIL/Apo2L-induced apoptosis. Anticancer Research 855-64

24. Yang XE, Chen WR, Feng Y (2007) Improving human micronutrient nutrition through biofortification in the soil-plant system: China as a case study. Environmental Geochemistry and Health 413-28

25. Singh P, Kim YJ, Wang C, Mathiyalagan R, Yang D (2016) The development of a green approach for the biosynthesis of silver and gold nanoparticles by using Panax ginseng root extract, and their biological applications. Artificial cells, nanomedicine, and biotechnology 1150-7

26. Arvizo RR, Bhattacharyya S, Kudgus RA, Giri K, Bhattacharya R, Mukherjee P (2012) Intrinsic therapeutic applications of noble metal nanoparticles: past, present and future. Chemical Society Reviews 2943-70

27. Ratan ZA, Haidere MF, Nurunnabi M, Shahriar SM, Ahammad AJ, Shim YY, Reaney MJ, Cho JY9 (2020) Green Chemistry Synthesis of Silver Nanoparticles and Their Potential Anticancer Effects. Cancers 855

28. Mannarmannan M, Biswas K (2019) Biological Activity of ZnO Nanoparticles Synthesized from the Dried Rinds of Garcinia Gummi Gutta. Chemistry Select $12739-42$

29. Mahamuni PP, Patil PM, Dhanavade MJ, Badiger MV, Shadija PG, Lokhande AC, Bohara RA (2019) Synthesis and characterization of zinc oxide nanoparticles by using polyol chemistry for their antimicrobial and antibiofilm activity. Biochemistry and biophysics reports 1;17:71-80 
30. Talam S, Karumuri SR, Gunnam N (2012) Synthesis, characterization, and spectroscopic properties of $\mathrm{ZnO}$ nanoparticles. ISRN Nanotechnology

31. Narayana A, Bhat SA, Fathima A, Lokesh SV, Surya SG, Yelamaggad CV (2020) Green and low-cost synthesis of zinc oxide nanoparticles and their application in transistor-based carbon monoxide sensing. RSC Advances 13532-42

32. Bisht G, Rayamajhi S (2016) ZnO nanoparticles: a promising anticancer agent. Nanobiomedicine 3-9

33. Frasconi M, Liu Z, Lei J, Wu Y, Strekalova E, Malin D, Ambrogio MW, Chen X, Botros YY, Cryns VL, Sauvage JP (2013) Photoexpulsion of surface-grafted ruthenium complexes and subsequent release of cytotoxic cargos to cancer cells from mesoporous silica nanoparticles. Journal of the American Chemical Society 11603-13

34. Hanley C, Thurber A, Hanna C, Punnoose A, Zhang J, Wingett DG (2009) The influences of cell type and $\mathrm{ZnO}$ nanoparticle size on immune cell cytotoxicity and cytokine induction. Nanoscale research letters 1409

35. Mozdoori N, Safarian S, Sheibani N (2017) Augmentation of the cytotoxic effects of zinc oxide nanoparticles by MTCP conjugation: Non-canonical apoptosis and autophagy induction in human adenocarcinoma breast cancer cell lines. Materials Science and Engineering 78:949-59

36. Cesselli D, Jakoniuk I, Barlucchi L, Beltrami AP, Hintze TH, Nadal-Ginard B, Kajstura J, Leri A, Anversa $P$ (2001) Oxidative stress-mediated cardiac cell death is a major determinant of ventricular dysfunction and failure in dog dilated cardiomyopathy. Circulation research 279-86

37. Mahmoud AM, Wilkinson FL, Sandhu MA, Dos Santos JM, Alexander MY (2019) Modulating Oxidative Stress in Drug-Induced Injury and Metabolic Disorders: The Role of Natural and Synthetic Antioxidants. Oxidative Medicine and Cellular Longevity

38. Gurunathan S, Qasim M, Park C, Yoo H, Kim JH, Hong K (2018) Cytotoxic potential and molecular pathway analysis of silver nanoparticles in human colon cancer cells HCT116. International journal of molecular sciences 2269

39. Shakila PB, Narendhran S, Arishiya NT, Kumar DN. Biosynthesis and characterization of $\mathrm{Cu} / \mathrm{ZnO}$ nanocomposite using lantana aculeate leaf extract: Evaluation of antioxidant, antibacterial and cytotoxic activity

40. Elmehy DA, Ismail HI, Soliman NA, Amer BS, Elkaliny HH, El-Ebiary AA, Gamea GA (2020) Oxidative stress mediated apoptotic potential of mefloquine on experimental trichinellosis. Acta Tropica 213:105760

41. Nanni V, Di Marco G, Sacchetti G, Canini A, Gismondi A (2020) Oregano Phytocomplex Induces Programmed Cell Death in Melanoma Lines via Mitochondria and DNA Damage. Foods 1486

42. Ashraf VM, Kalaichelvan VK, Ragunathan R, Venkatachalam VV (2020) Apoptosis Induction and Anticancer Activity of 2, 4-bis (1-phenylethyl) Phenol from Clerodendrum thomsoniae Balf. f. in vitro. International Journal of Pharmaceutical Investigation 542-7

43. Kang MH, Reynolds CP (2009) Bcl-2 inhibitors: targeting mitochondrial apoptotic pathways in cancer therapy. Clinical cancer research 1126-32 
44. Pistritto G, Trisciuoglio D, Ceci C, Garufi A, D'Orazi G. Apoptosis as anticancer mechanism: function and dysfunction of its modulators and targeted therapeutic strategies. Aging (Albany NY). 2016 Apr;8(4):603.

45. Vardiyan R, Ezati D, Anvari M, Ghasemi N, Talebi A (2020) Effect of L-carnitine on the expression of the apoptotic genes Bcl-2 and Bax. Clinical and Experimental Reproductive Medicine 155

46. Ivanova D, Zhelev Z, Aoki I, Bakalova R, Higashi T (2016) Overproduction of reactive oxygen speciesobligatory or not for induction of apoptosis by anticancer drugs. Chinese Journal of Cancer Research 383

47. Lee CH, Lin MS, Chi CW, Chen YJ, Wang GS, Liao KW, Chiu LP, Wu SH, Huang DM, Chen L, Shen YS (2020) ZnO nanoparticles induced caspase-dependent apoptosis in gingival squamous cell carcinoma through mitochondrial dysfunction and p70S6K signaling pathway. International journal of molecular sciences 1612

\section{Figures}

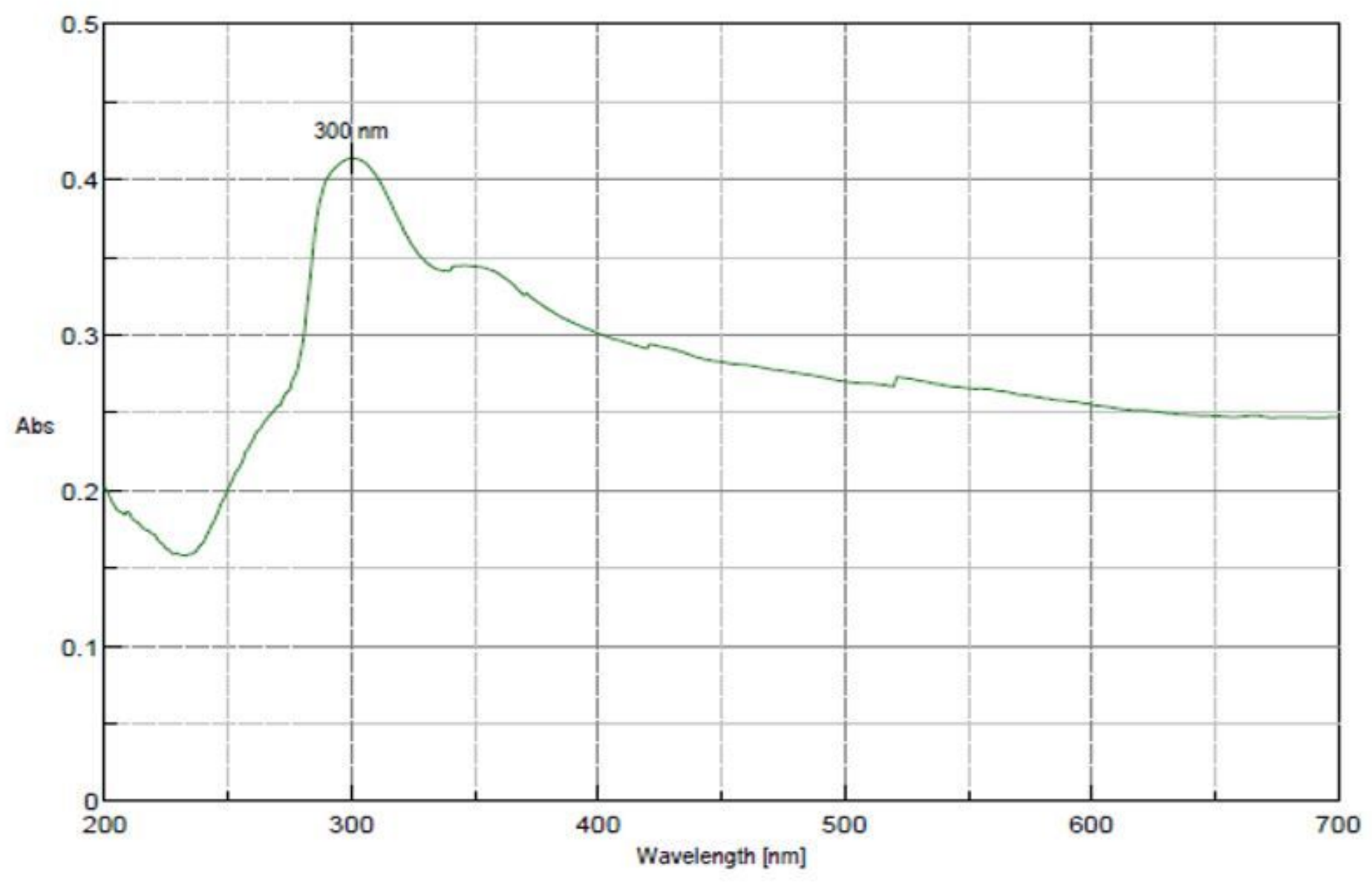

Figure 1 
UV-Vis spectra of synthesized ZnONPs from Gymnemasylvestre. The strong absorption spectrum of ZnONPs exhibited at $300 \mathrm{~nm}$.

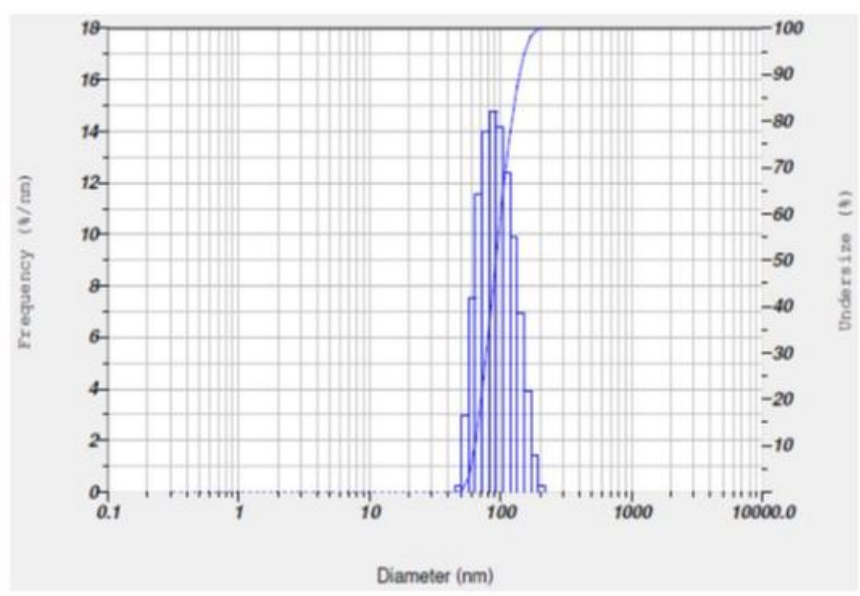

Calculation Results
\begin{tabular}{|c|c|c|c|c|}
\hline Peak No. & S.P.Area Ratio & Mean & S. D. & Mode \\
\hline 1 & 1.00 & $97.6 \mathrm{~nm}$ & $29.4 \mathrm{~nm}$ & $87.6 \mathrm{~nm}$ \\
\hline 2 & - & $-\mathrm{nm}$ & $-\mathrm{nm}$ & $-\mathrm{nm}$ \\
\hline 3 & - & $--\mathrm{nm}$ & $--\mathrm{nm}$ & $-\mathrm{nm}$ \\
\hline Total & 1.00 & $97.6 \mathrm{~nm}$ & $29.4 \mathrm{~nm}$ & $87.6 \mathrm{~nm}$ \\
\hline
\end{tabular}

Cumulant Operations

Z-Average

: $81.1 \mathrm{~nm}$

PI

: 0.681

Molecular weight measurement

Molecular weight

Mark-Houwink-Sakurada parameters : :--

Figure 2

Particle size analysis of ZnONPs synthesized using the leaf extract of Gymnemasylvestre

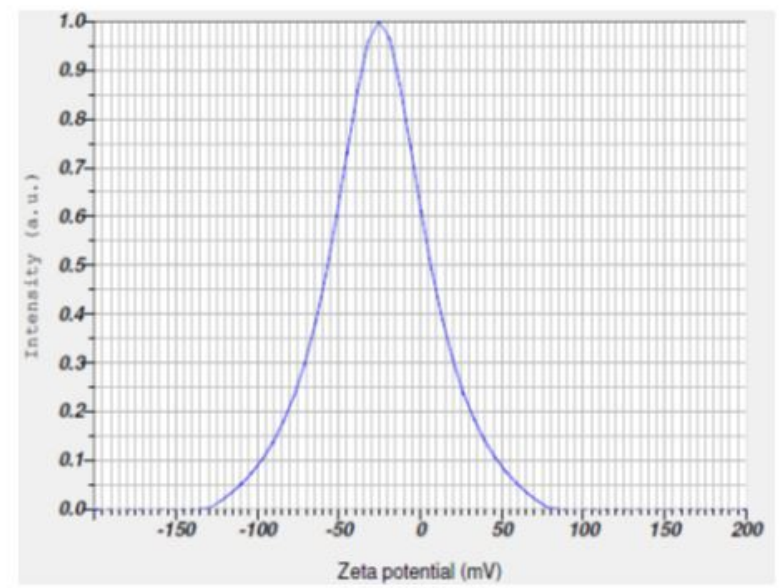

Calculation Results

\begin{tabular}{|c|c|c|}
\hline Peak No. & Zota Potential & Electrophonetic Mobility \\
\hline 1 & $.25 .1 \mathrm{mV}$ & $0.000195 \mathrm{~cm} 2 / \mathrm{s}$ \\
\hline 2 & $-=\mathrm{mV}$ & $=\mathrm{cm} 2 / \mathrm{s}$ \\
\hline 3 & $-=\mathrm{mV}$ & $=\mathrm{cm} 2 / \mathrm{s}$ \\
\hline
\end{tabular}

Zeta Potential (Mean)

$: 25.1 \mathrm{~mW}$

Electrophoretic Mobility mean

: $0.000195 \mathrm{~cm} 2 \mathrm{Ns}$

\section{Figure 3}

Zeta potential analysis of ZnONPs synthesized using the leaf extract of Gymnemasylvestre 


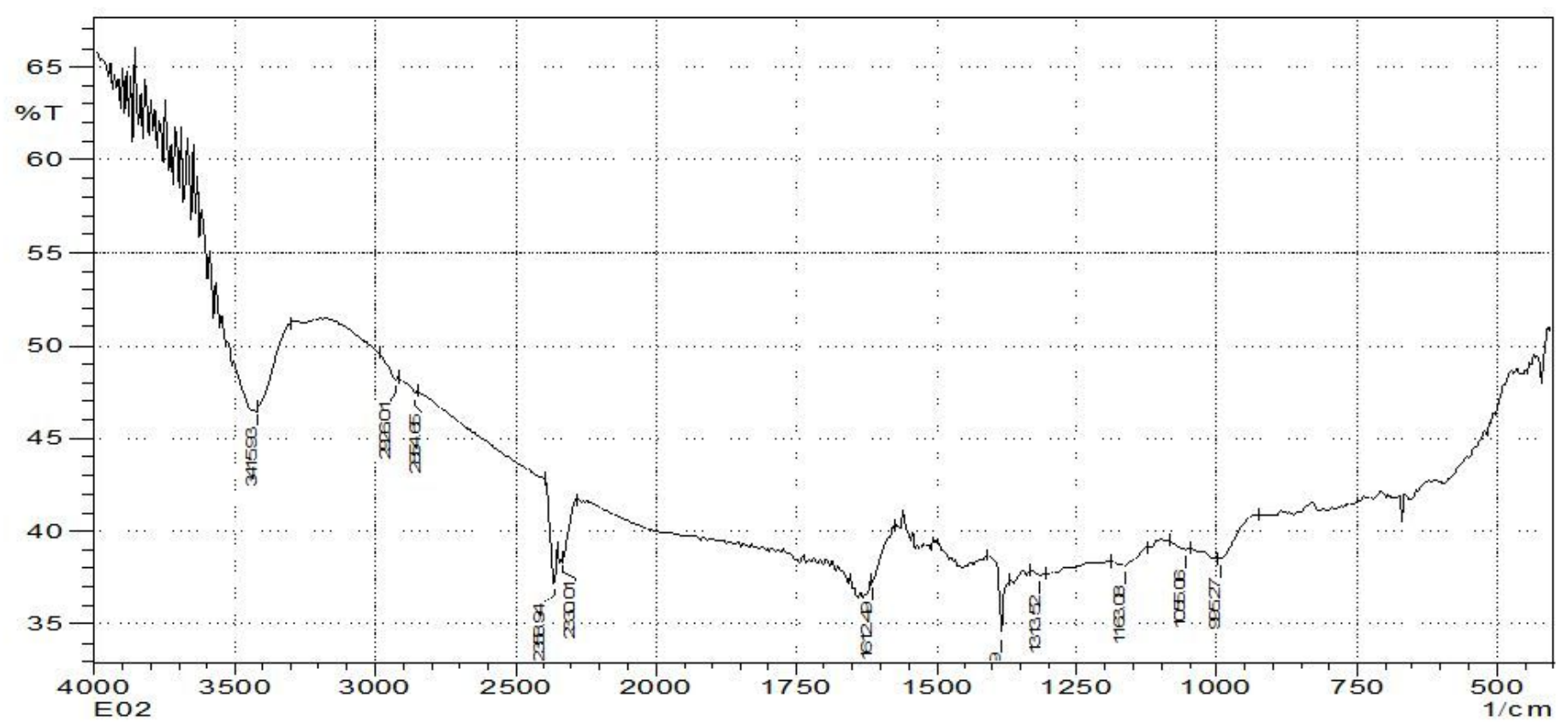

Figure 4

FTIR analysis of ZnONPs synthesized using the leaf extract of Gymnemasylvestre

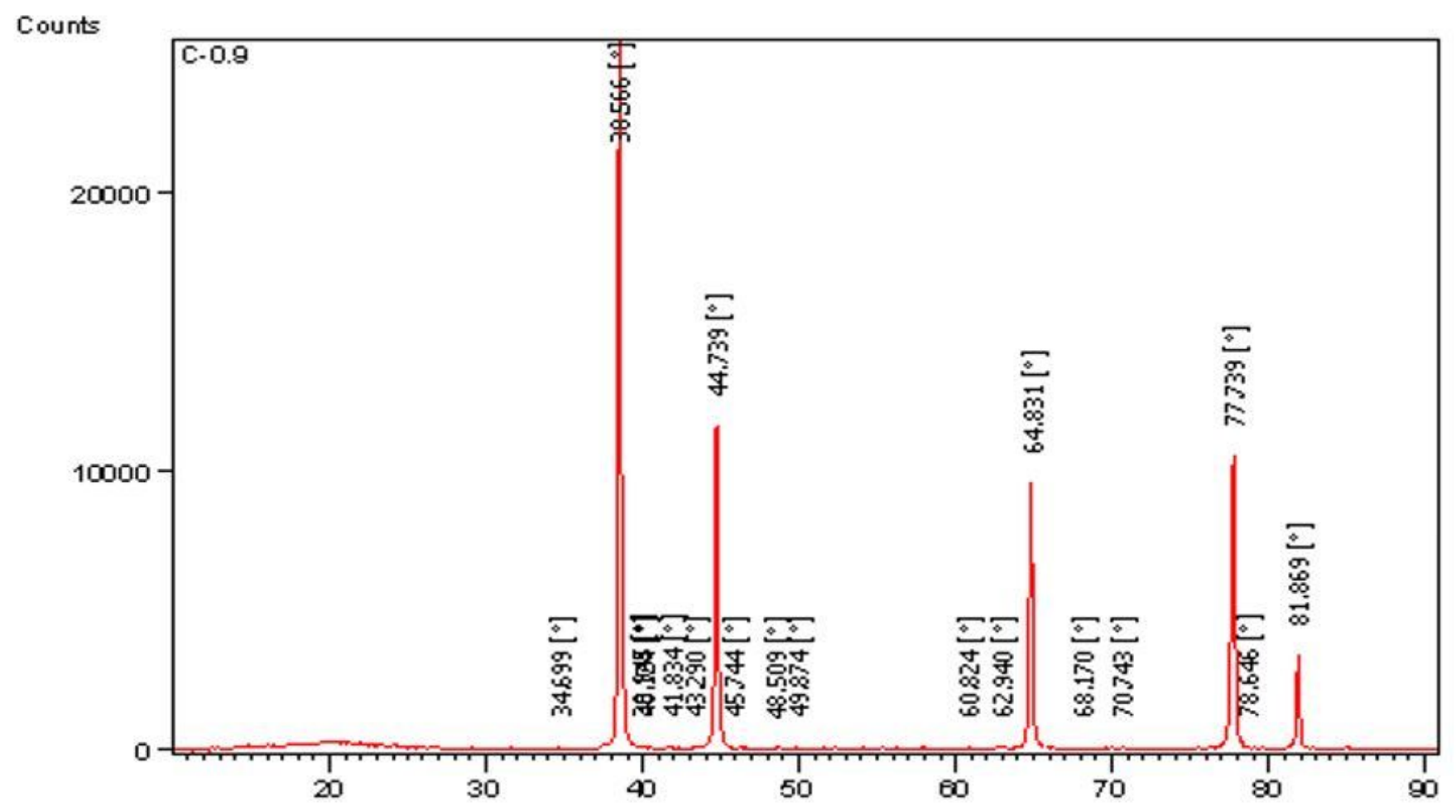

Figure 5 
XRD analysis of ZnONPs synthesized using the leaf extract of Gymnemasylvestre

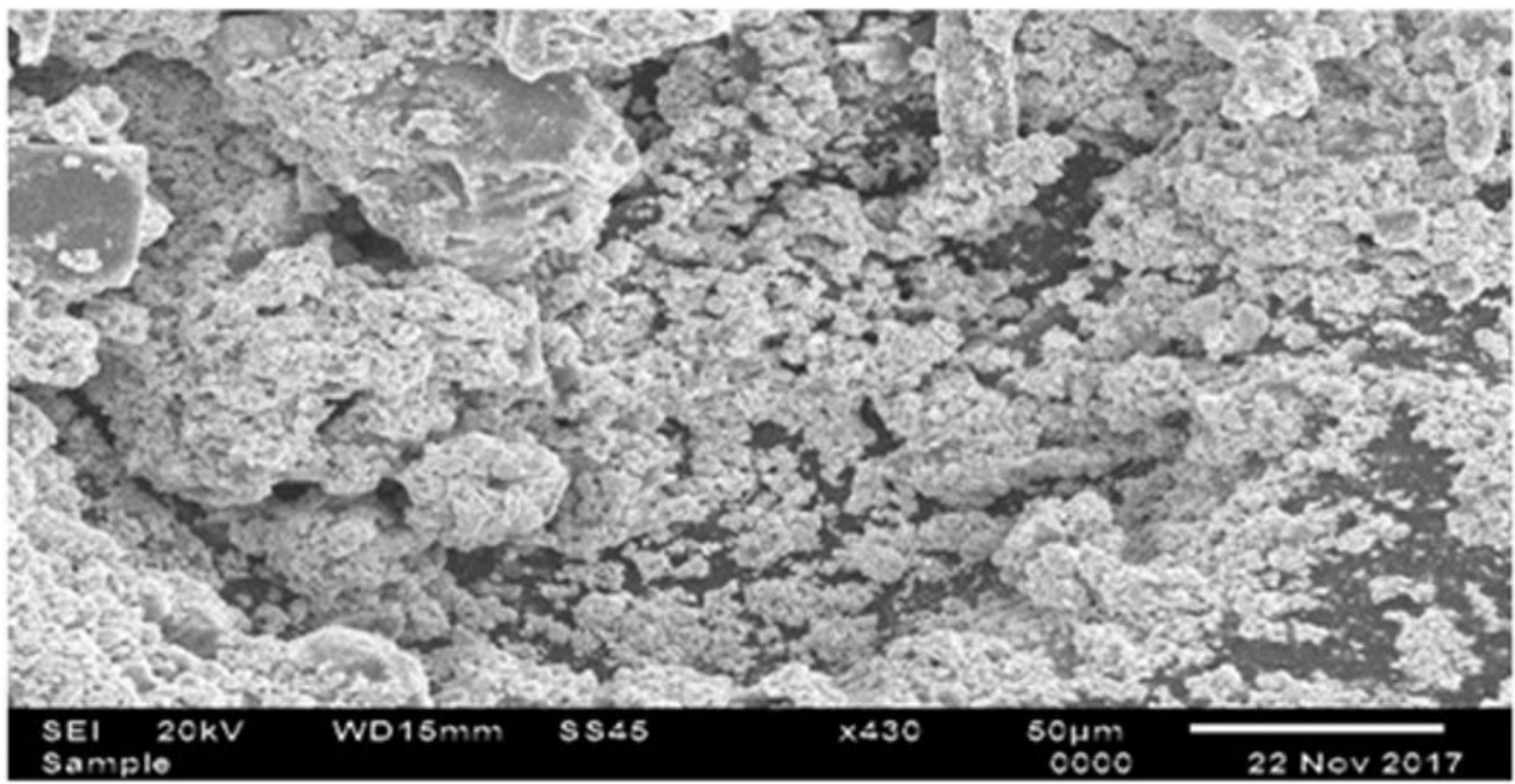

Figure 6

SEM analysis of ZnONPs synthesized using the leaf extract of Gymnemasylvestre

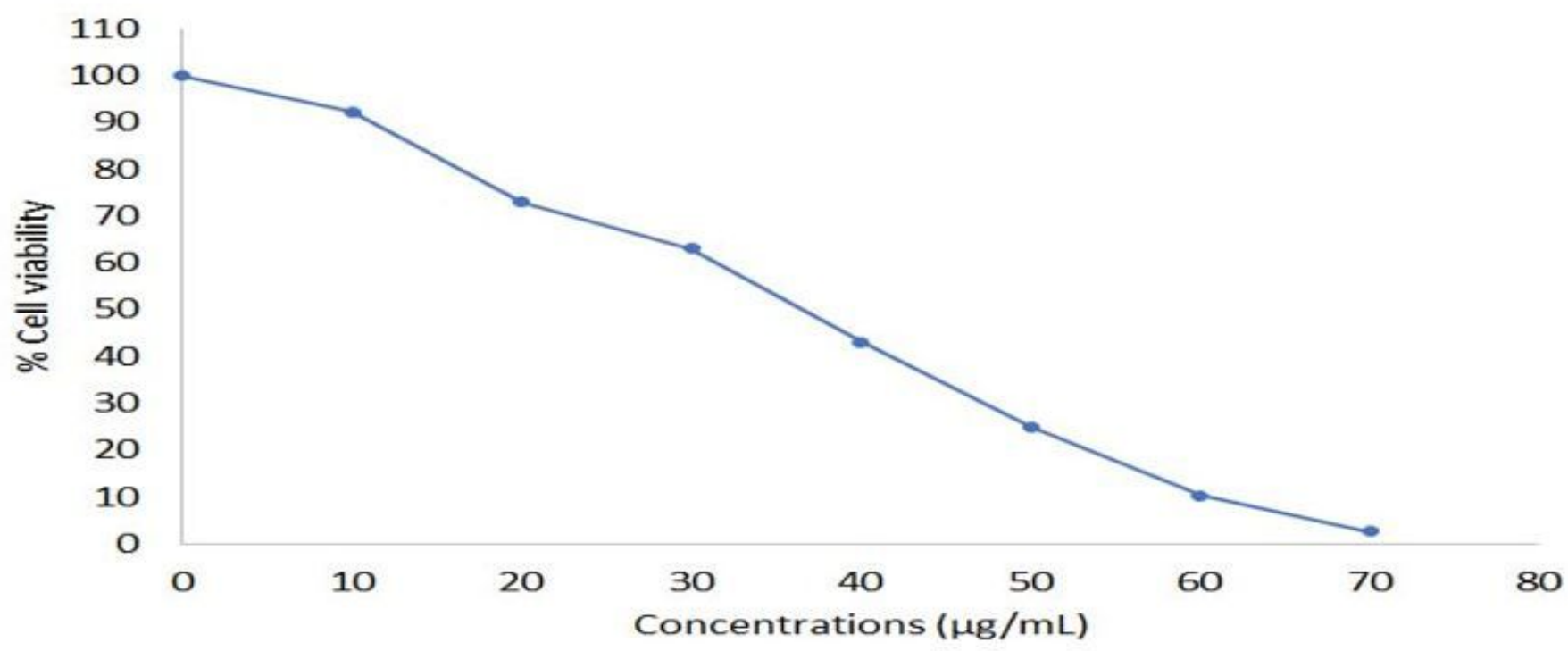

IC50 for ZnONPs-GS: $36 \mu \mathrm{g} / \mathrm{mL}$

IC25 for ZnONPs-GS: $50 \mu \mathrm{g} / \mathrm{mL}$

Figure 7 
The cytotoxic effect of ZnONPs-GS on MCF-7 cells was determined by MTT assay.

A)

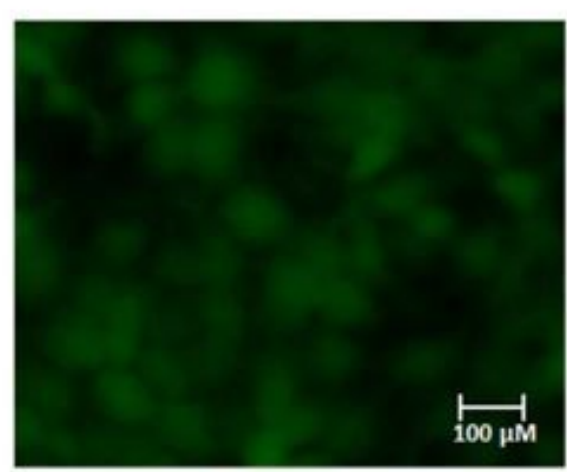

Control

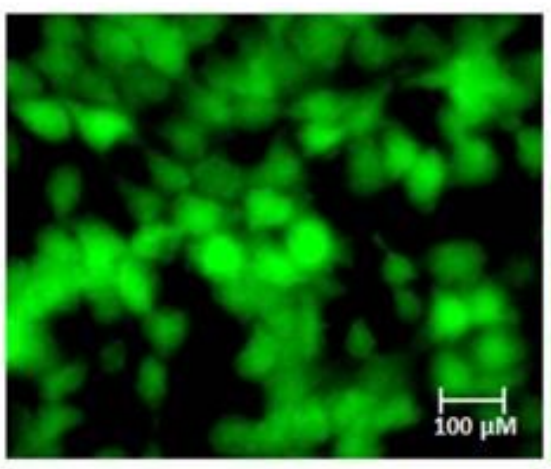

ZnONPs-GS (36 $\mu \mathrm{g} / \mathrm{mL})$ B)

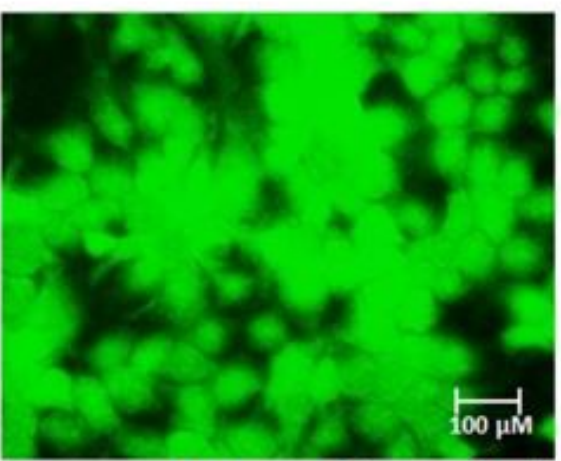

ZnONPs-GS $(50 \mu \mathrm{g} / \mathrm{mL})$

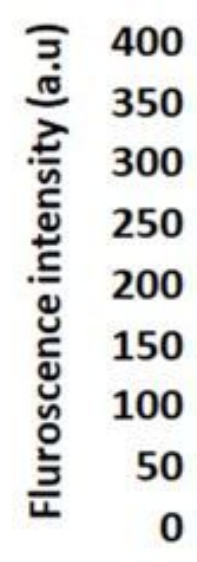

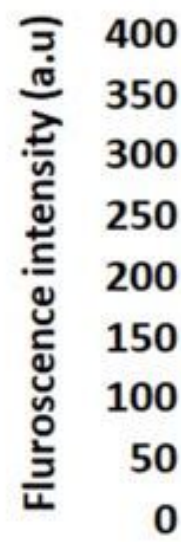

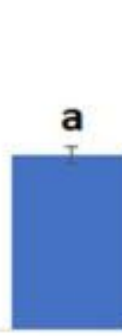

Control

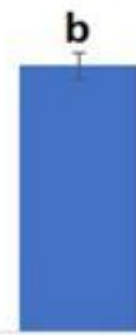

ZnONPs-GS (36 $\mu \mathrm{g} / \mathrm{mL})$

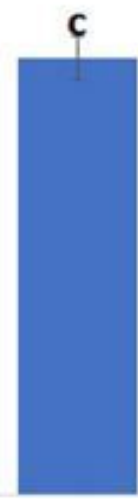

ZnONPs-GS (50

$\mu \mathrm{g} / \mathrm{mL})$

A) Fluorescence microscopic image for ZnONPs-GS on intracellular ROS generation. Percentage of ROS generation was detected by spectrofluorometer. B) The data represent mean \pm SD of triplicate, $* P<0.05$ as compared with the control group.

\section{Figure 8}

The effect of ZnONPs-GS on intracellular ROS generation was analyzed in MCF-7 cells by using DCFH-DA staining. 
A)

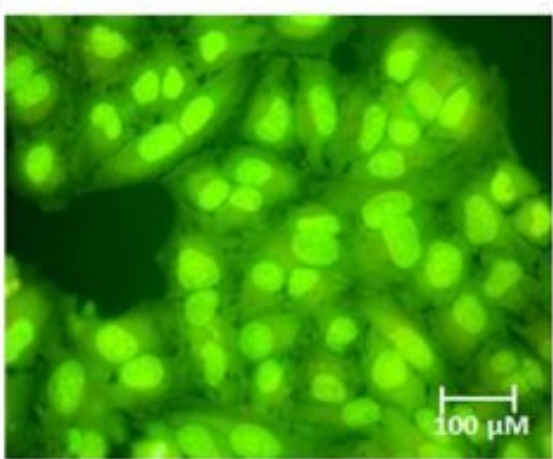

Control

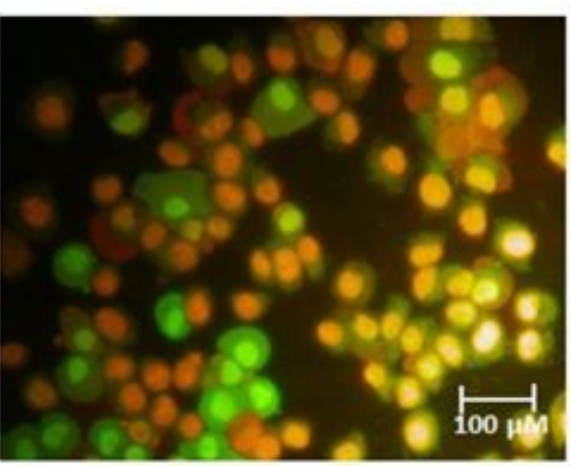

ZnONPs-GS $(36 \mu \mathrm{g} / \mathrm{mL})$

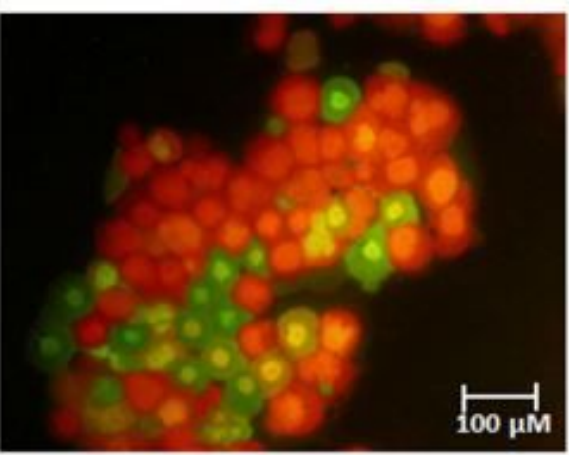

ZnONPs-GS $(50 \mu \mathrm{g} / \mathrm{mL})$

B)

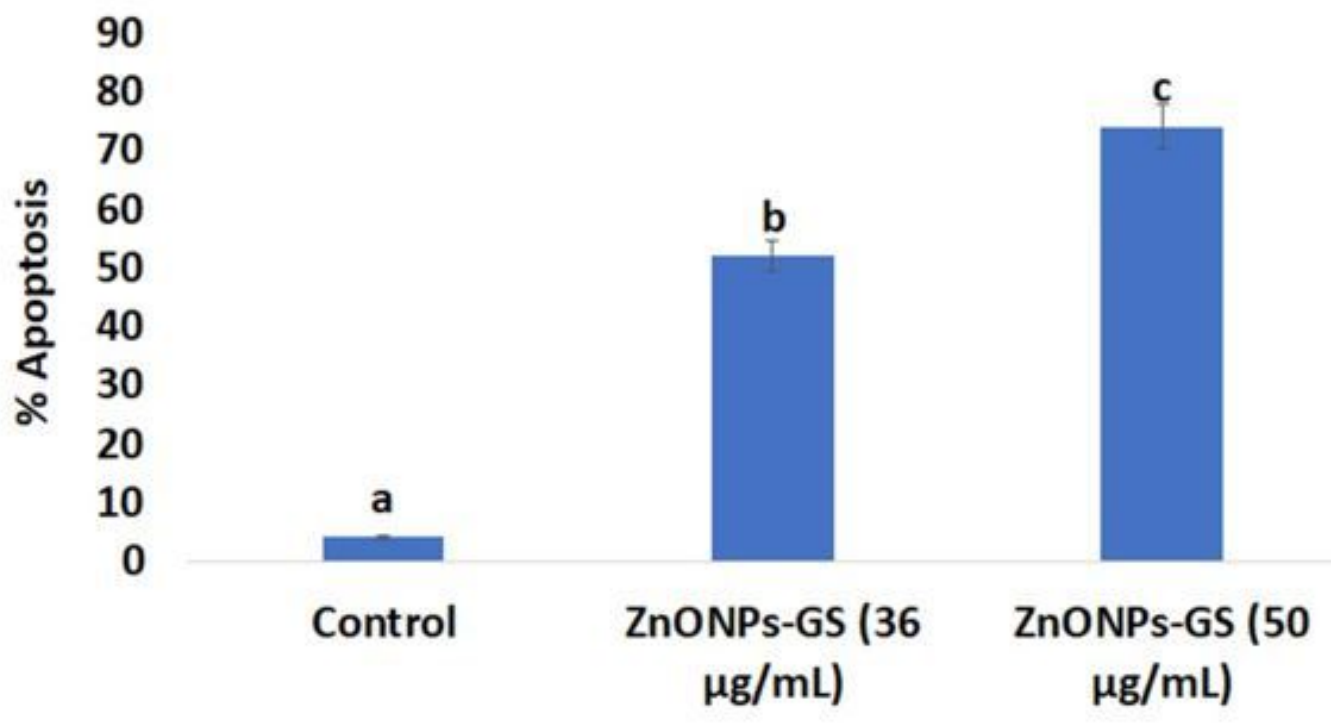

A) Fluorescence microscopic image for ZnONPs-GS on apoptotic morphological status by acridine orange and ethidium bromide staining. B) Bar diagram represents percentage of apoptosis. The data represent mean $\pm \mathrm{SD}$ of triplicate, ${ }^{*} P<0.05$ as compared with the control group.

Figure 9

ZnONPs-GS induces apoptotic morphological changes in MCF-7 cells. 


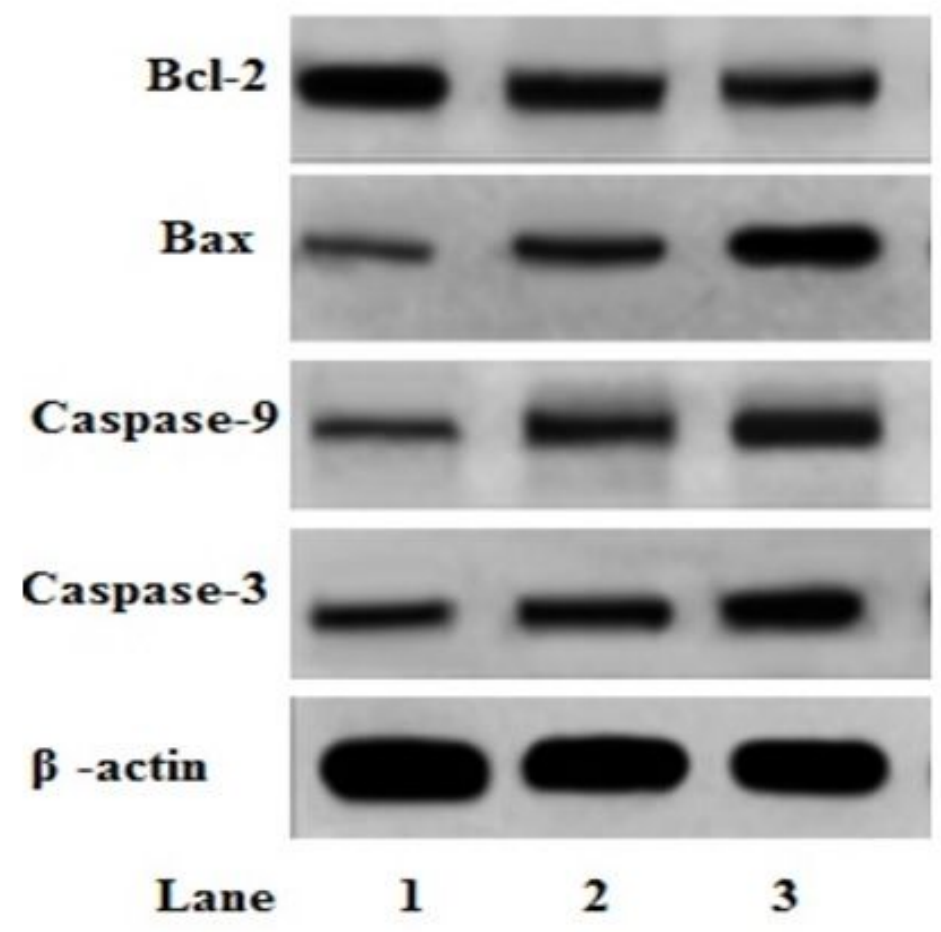

Western blots images for Bax, Bcl-2 caspase-9 and caspase-3 in MCF-7 cell lines. Lane 1: Control; Lane 2: ZnONPs-GS (36 $\mu \mathrm{g} / \mathrm{mL})$; Lane 3: ZnONPs-GS $(50 \mu \mathrm{g} / \mathrm{ml}$. The interests of proteins were normalized to respective $\beta$-actin loading control. The data represent mean $\pm \mathrm{SD}$ of triplicate, ${ }^{*} \mathrm{P}<0.05$ as compared with the control group.

Figure 10

ZnONPs-GS induces apoptotic marker expression in MCF-7 cells 